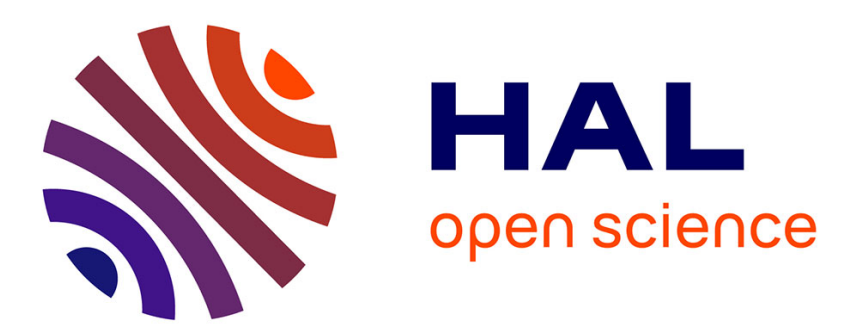

\title{
Adaline Neural Networks-based Sensorless Control of Five-Phase PMSM Drives
}

Ngac Ky Nguyen, Eric Semail, Frederic de Belie, Xavier Kestelyn

\section{To cite this version:}

Ngac Ky Nguyen, Eric Semail, Frederic de Belie, Xavier Kestelyn. Adaline Neural Networks-based Sensorless Control of Five-Phase PMSM Drives. IECON 2016 - 42nd Annual Conference of the IEEE Industrial Electronics Society, Oct 2016, Florence, Italy. pp.6. hal-03170426

\section{HAL Id: hal-03170426 https://hal.science/hal-03170426}

Submitted on 16 Mar 2021

HAL is a multi-disciplinary open access archive for the deposit and dissemination of scientific research documents, whether they are published or not. The documents may come from teaching and research institutions in France or abroad, or from public or private research centers.
L'archive ouverte pluridisciplinaire HAL, est destinée au dépôt et à la diffusion de documents scientifiques de niveau recherche, publiés ou non, émanant des établissements d'enseignement et de recherche français ou étrangers, des laboratoires publics ou privés. 


\title{
Adaline Neural Networks-based Sensorless Control of Five-Phase PMSM Drives
}

\author{
Ngac Ky Nguyen*, Eric Semail*, Frederic De Belie ${ }^{\dagger}$, Xavier Kestelyn* \\ ${ }^{*}$ Univ. Lille, Centrale Lille, Arts et Metiers ParisTech, HEI, EA 2697 \\ L2EP - Laboratoire d'Electrotechnique et d'Electronique de Puissance, F-59000 Lille, France \\ Email:\{ngacky.nguyen; eric.semail; xavier.kestelyn\}@ensam.eu \\ ${ }^{\dagger}$ Electrical Energy Laboratory, Ghent University \\ Technologiepark 913, Zwijnaarde, Belgium \\ Email: Frederik.DeBelie@UGent.be
}

\begin{abstract}
This papers presents a sensorless control for fivephase PM synchronous machines. An adaptive method, based on a linear neural network called Adaline (Adaptive Linear Neural Networks), has been achieved to estimate the rotor position with a high precision even at low speed without high frequency signal injection. Non-sinusoidal three-phase PM machines require more complex algorithm for sensorless control because of harmonics in the back-EMF. This is not the case for multiphase PM machines thanks to the property of equivalent machines in the eigenspace. Some given simulation and experimental results in laboratory confirm the possibility of real-time implementation of Adaline networks and the good performance of sensorless control based on this.
\end{abstract}

\section{INTRODUCTION}

$\mathbf{M}^{2}$ ORE than ever, industrial systems such as automotive, ships and planes need compactness, robustness and very high reliability. In term of reliability, this is particularly true for electrical vehicles where the electrical part falls generally in faulty mode more often than the others. If three-phase drives are used, an oversize is obvious and the drive has to be stopped if a fault occurs. Now, a high reliability could be achieved by using multiphase drives which present some advantages comparing to three-phase ones in term of faulttolerance, compactness, etc [1]-[3].

Recently, sensorless control is proposed for systems where the compactness is a high constraint or for increasing the reliability of systems since sensorless control can be considered as an urgent solution when position sensors are in fault. For self-sensing control, one advantage of multiphase PMSM comparing to three-phase one is the existence of some equivalent fictitious diphase machines after a transformation of $n$ electrical variables (voltages, currents, back-electromotive forces (back-EMFs), etc.) into a new base (eigenspace). Indeed, each fictitious machine is characterized by a quasisinusoidal back-EMF even if the back-EMF of the real $n$ phase machine is non-sinusoidal [4]. This point does not exist in non-sinusoidal three-phase machines where the observer's performance is generally affected by harmonics of the backEMFs.

In [5], a state of the art about a sensorless control is given for PMSM. There are two families of sensorless control methods.
The first one is based on the PMSM model with the fundamental extraction. The limit of this approach is expressed at very low or zero-speed operation when the fundamental of backEMF, voltage and current is almost equal or equal to zero. That is why the second approach has been studied specially for this operating point. Indeed, a high-frequency injection (sinusoidal or pulse signals) is superimposed to the fundamental frequency signal for rotor position detection thanks to the exploitation of PMSM feature of magnetic saliency [6], [7].

Authors in [8], [9] work on the impact of machine design using fractional-slot stator to improve the performance of sensorless control for three-phase PMSM. By proposing a small iron teeth between each couple of PMs, a high rotor saliency is obtained, resulting in a good position tracking performance.

In [10], a 5-phase PMSM fault-tolerant sensorless control has been proposed by using an adaptive neural network for fault detection. However, the used sensorless approach was based on a classical Phase Lock-Loop (PLL). In [11], a sensorless-based direct torque control for 5-phase PMSM has been done. In this work, the stator flux vector in the Concordia frame (only the first harmonic of voltages is considered since the PMSM is supposed to be sinusoidal) is estimated by integrating the voltage. Then, the rotor position is calculated from the angle of flux vector and the load angle. In [12], an iterative control based on an algorithm called CORDIC for sensorless 5-phase PMSM control has been proposed. Indeed, voltages are calculated iteratively by a recursive form and the difference angle (between the real angle of rotor and the estimated one) is obtained for each iteration. Then, a PI controller is used to obtain the rotor speed. However, the limit of this approach is shown at zero speed where it is necessary to start the drive in open-loop (torque control). A self-sensing control method has been proposed for 5-phase PMSM drive under open-circuit fault conditions in [13]. One and two open-phases have been considered. In case of a fault, the back-EMFs, voltages and currents waveforms projected in the Concordia frame which are sinusoidal in healthy mode become nonsinusoidal. This property has an impact on the performance of the position tracking based on a PLL. To solve this, an nouvel transformation matrix was proposed corresponding to 
each case of fault, to separate the 1st harmonics from the $3 \mathrm{rd}$ harmonics of the back-EMFs so that the PLL could be applied with success.

The work proposed in this paper improves the one presented in [13]. Performance of position tracking can be improved by replacing the PLL by an Adaline neural network. In general, neural networks require a lot of iterations, e.g a huge calculus time, to converge. This drawback is not suitable in real time applications. However, Adaline, known as a linear function of non-linear inputs, will give a very fast convergence if the inputs are well defined as it has been shown in some previous work [14]. This property has been exploited in [15], [16] for frequency estimation of power grids and active power filters. Contrary to multilayer neural networks, the weight of Adaline after convergence could be exploited for parameter estimations, i.e the position of rotor in our study case.

\section{5-PHASE PM SYNCHRONOUS MACHINE MODELING}

Let us define:

$$
\begin{gathered}
{[\mathbf{v}]=\left[\begin{array}{lllll}
v_{a} & v_{b} & v_{c} & v_{d} & v_{e}
\end{array}\right]^{T}} \\
{[\mathbf{i}]=\left[\begin{array}{lllll}
i_{a} & i_{b} & i_{c} & i_{d} & i_{e}
\end{array}\right]^{T}} \\
{[\mathbf{e}]=\left[\begin{array}{lllll}
e_{a} & e_{b} & e_{c} & e_{d} & e_{e}
\end{array}\right]^{T}}
\end{gathered}
$$

where $[\mathbf{v}]$ is the voltage vector, $[\mathbf{i}]$ is the current vector and $[\mathbf{e}]$ is the back-EMF vector of the PMSM machine.

Assuming no magnetic saturation and no saliency, the voltage equation is given by:

$$
[\mathbf{v}]=R_{s}[\mathbf{i}]+[\mathbf{L}] \frac{d[\mathbf{i}]}{d t}+[\mathbf{e}]
$$

where:

$$
[\mathbf{L}]=\left[\begin{array}{ccccc}
L & M_{1} & M_{2} & M_{2} & M_{1} \\
M_{1} & L & M_{1} & M_{2} & M_{2} \\
M_{2} & M_{1} & L & M_{1} & M_{2} \\
M_{2} & M_{2} & M_{1} & L & M_{1} \\
M_{1} & M_{2} & M_{2} & M_{1} & L
\end{array}\right]
$$

with $R_{s}$ as the stator resistance, $L, M_{1}$ and $M_{2}$ as the stator self and mutual inductances.

According to the multiphase theory in [4], a real multiphase machine can be decomposed to several fictitious machines in a new base thanks to a specific transformation. These obtained machines are magnetically decoupled but mechanically coupled since the total torque is a sum of each fictitious machine. A well-known Concordia transformation is usually used to bring the inductance matrix given in (5) into the eigenspace where there is existing one homopolar machine and two diphase machines characterized by $L_{0},\left[\mathbf{L}_{\alpha_{1} \beta_{1}}\right]$ and $\left[\mathbf{L}_{\alpha_{3} \beta_{3}}\right]$ (eigenvalues of the inductance matrix) respectively. Equations that link the voltage, the current and the back-EMF of each fictitious machine are given by:

$$
v_{0}=R_{s} i_{0}+L_{0} \frac{d i_{0}}{d t}+e_{0}
$$

$$
\begin{aligned}
& {\left[\mathbf{v}_{\alpha_{1} \beta_{1}}\right]=R_{s}\left[\mathbf{i}_{\alpha_{1} \beta_{1}}\right]+\left[\mathbf{L}_{\alpha_{1} \beta_{1}}\right] \frac{d\left[\mathbf{i}_{\alpha_{1} \beta_{1}}\right]}{d t}+\left[\mathbf{e}_{\alpha_{1} \beta_{1}}\right]} \\
& {\left[\mathbf{v}_{\alpha_{3} \beta_{3}}\right]=R_{s}\left[\mathbf{i}_{\alpha_{3} \beta_{3}}\right]+\left[\mathbf{L}_{\alpha_{3} \beta_{3}}\right] \frac{d\left[\mathbf{i}_{\alpha_{3} \beta_{3}}\right]}{d t}+\left[\mathbf{e}_{\alpha_{3} \beta_{3}}\right]}
\end{aligned}
$$

It should be noticed that the homopolar machine is created by harmonics $n, 2 n, \ldots, n \cdot k$ with $n$ number of phases, the main machine $\alpha_{1} \beta_{1}$ is created by harmonics $1,9,11, \ldots, n \cdot k \pm$ 1 and harmonics $3,7,13, \ldots, n \cdot k \pm 2$ present in the auxiliary machine.

For trapezoidal back-EMFs, the $\left[\mathbf{e}_{\alpha_{1} \beta_{1}}\right]$ and $\left[\mathbf{e}_{\alpha_{3} \beta_{3}}\right]$ are not purely sinusoidal but very close because of low magnitudes of the 7th and the 9th harmonics present in a trapezoidal backEMF. As a consequence, this property is very interesting to estimate the back-EMF by observers compared to 3-phase nonsinusoidal machine.

The electromagnetic torque of the 5-phase PMSM is expressed as:

$$
T_{\text {total }}=T_{1}+T_{3}
$$

where : $T_{1} \Omega=\left[\mathbf{e}_{\alpha_{1} \beta_{1}}\right]^{T}\left[\mathbf{i}_{\alpha_{1} \beta_{1}}\right]$ et $T_{3} \Omega=\left[\mathbf{e}_{\alpha_{3} \beta_{3}}\right]^{T}\left[\mathbf{i}_{\alpha_{3} \beta_{3}}\right]$.

Equations (7) and (8) offer two possibilities for back-EMF observation. The 1st one is based on the main machine with a high amplitude of the back-EMF. The second one can be achieved by working on the 3rd harmonics. Despite the third harmonic having a lower amplitude compared to the 1st harmonics, but an observer based on the 3rd harmonics could offer a higher precision due to more information per mechanical revolution thanks to a frequency 3 times greater. It is also possible to develop a hybrid observer. At high speed, the 3 harmonics are used and at low speed, it is advised to use the fundamental signals. In this work, we focus only at the 1st harmonics.

\section{IDEA OF USING ADALINE}

\section{A. Adaline: structure and applications}

The Adaline neural network was originally conceived and formulated by Widrow [14]. Based on the LMS (Least Mean Square) learning rule, this model represents a classic example of the simplest intelligent self-learning system that can adapt itself to achieve a given linear modeling task. The problem consists in finding a suitable set of weights such that the input-output behavior of the Adaline becomes close to a set of desired input-output data points linked with a linear relationship.

Because the Adaline is well-suited and ideal for approximating and learning linear relations, it will thus be used to learn the expressions previously developed. The Adaline weights are adjusted according to:

$$
[\mathbf{w}]_{k+1}=\frac{[\mathbf{w}]_{k}+\eta \cdot \epsilon_{k} \cdot[\mathbf{x}]_{k}}{[\mathbf{x}]_{k}^{T} \cdot[\mathbf{x}]_{k}}
$$

where $[\mathbf{x}]$ is the input vector, $\eta$ is a learning rate chosen between 0 and 1 , and $\epsilon$ is the error. This error is the difference between a reference signal $y_{k}^{d}$ and $y_{k}$, the estimated output of the Adaline, therefore at each sampling time $\epsilon_{k}=y_{k}^{d}-y_{k}$. 


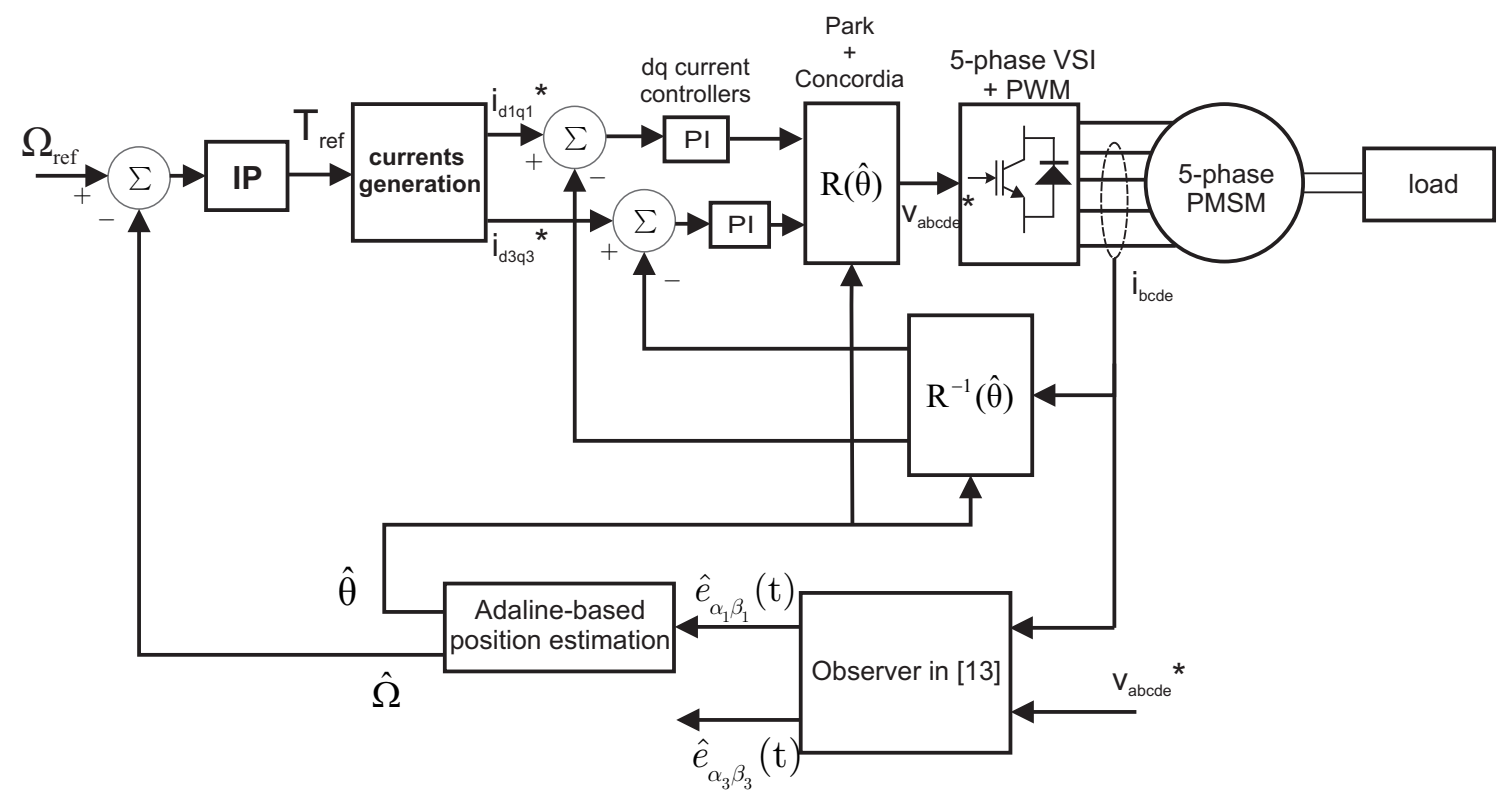

Fig. 1. Control scheme with Adaline-based position estimation.

\section{B. Adaline for 5-phase PM sensorless control}

The proposed control scheme is given in Fig. 1. An IP regulator is used for the speed and two PI controllers are employed for d-q currents issue from a current generation based on the MTPA strategy presented in [2], [17]. The measured currents and the references of voltages (issue from currents controllers) have been used as inputs of the observer proposed in [13]. The main contribution of this paper compared to the work presented in [13] consists of the proposition to use the Adaline network to track the rotor position instead of a classical PLL which is sensitive to the harmonics of the back-EMF and to the parameters of the used PI regulation. A comparison of performance will be given by simulation and experimental tests.

Indeed, the Adaline-based position estimation proposed thereafter is inspired from [15], [16] which is originally used for an adaptive phase detection of the power grid for shunt active power filter. This neural approach uses the observed back-EMF component $\hat{e}_{\alpha_{1}}(t)$ (or $\hat{e}_{\beta_{1}}(t)$ ) resulting from the observer presented in [13]. Of course, the quality of the observer is depending on the accurate knowledge of the machine parameters. This work will not focus on this aspect and supposes that all parameters are well-known for simulation and experimentation tests.

So, the back-EMF $\hat{e}_{\alpha_{1}}(t)$ component can be expressed by:

$$
\hat{e}_{\alpha_{1}}(t)=\sqrt{2} E_{1} \sin \theta
$$

where $\theta=p \Omega t$ in the steady state. $p$ is the pole pairs number. Expressing $\hat{e}_{\alpha_{1}}\left(t-t_{1}\right)$ and $\hat{e}_{\alpha_{1}}\left(t-2 t_{1}\right)$ leads to an iterative expression of (11) which is:

$$
\hat{e}_{\alpha_{1}}(t)=\left(2 \cos p \Omega t_{1}\right) \hat{e}_{\alpha_{1}}\left(t-t_{1}\right)-\hat{e}_{\alpha_{1}}\left(t-2 t_{1}\right)
$$

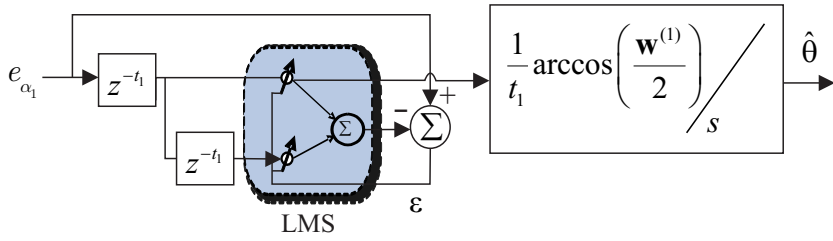

Fig. 2. Neural adaptive position estimation scheme.

(12) is a linearly separable equation which can therefore be estimated by an Adaline. By choosing $\hat{e}_{\alpha_{1}}(t)$ as its desired output and by using an input vector $[\mathbf{x}]=$ $\left[\begin{array}{ll}\hat{e}_{\alpha_{1}}\left(t-t_{1}\right) & \hat{e}_{\alpha_{1}}\left(t-2 t_{1}\right)\end{array}\right]^{T}$, the Adaline delivers an estimation of $\hat{e}_{\alpha_{1}}(t)$. Through the LMS learning, the weights converge to

$$
\mathbf{w}=\left[\begin{array}{ll}
2 \cos \left(p \Omega t_{1}\right) & -1
\end{array}\right]^{T}
$$

and the rotor speed can be obtained from $\mathbf{w}^{(1)}$, the first element of $\mathbf{w}$, by

$$
p \widehat{\Omega}=\frac{1}{t_{1}} \arccos \frac{\mathbf{w}^{(1)}}{2} .
$$

The functional block diagram of this Adaline-based approach is shown by Fig. 2 which also shows how $\hat{\theta}$ is extracted from the Adaline's first weight.

This neural approach demonstrates a good behavior in terms of the performance and robustness. It should be noticed that $\hat{\Omega}$ depends on $t_{1}$. The performance of this approach are influenced by the choice of $t_{1}$ and by the presence of the harmonics in the back-EMF. For this case, a detailed study is given in [16] where a neural symmetrical components extraction method has been presented to extract the fundamental of the back-EMF.

The next sections will give some simulation and experimental results to confirm the validity of the proposed method. 


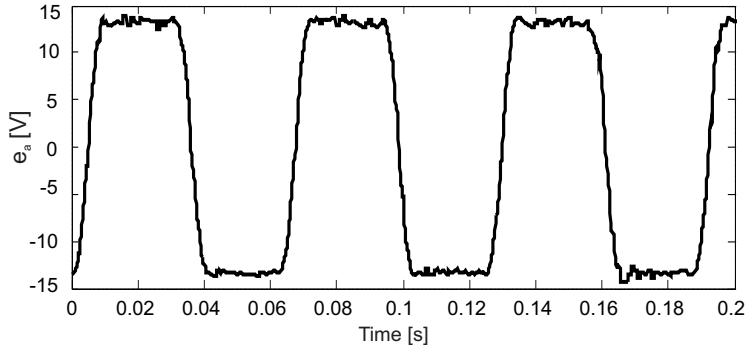

Fig. 3. (Experimental) Back-EMF of the 5-phase machine at $\Omega=50[\mathrm{rad} / \mathrm{s}]$.

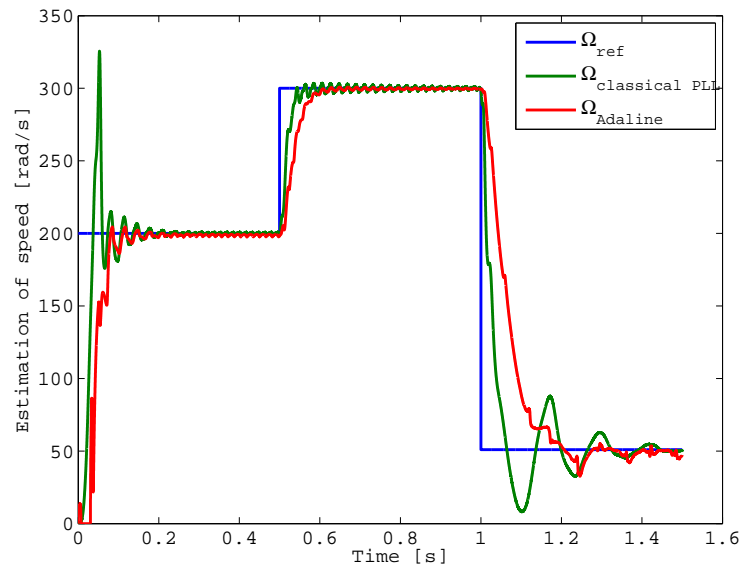

Fig. 4. (Simulation) Electrical speed estimations obtained with a classical PLL in [13] Vs Adaline [rad/s].

\section{Simulation Results}

The speed control scheme of Fig. 1 has been employed in Matlab/Simulink for simulation. The speed and current controllers design are based on the symmetrical optimum method.

Fig. 3 shows the back-EMF of the PMSM measured experimentally at $50[\mathrm{rad} / \mathrm{s}]$. It can be seen that this trapezoidal shape of the back-EMF induces also the 9th harmonic to $\hat{e}_{\alpha_{1}}$. As a consequence, a fundamental component extraction based on an Adaline neural network in [16] has been used.

Fig. 4 and Fig. 5 give the estimation of the electrical speed and the electrical position respectively obtained with a classical PLL (based on a PI controller) and with the Adaline. At high speed, both of them work correctly except there is a high windup of the speed at the beginning with the classical PLL for position tracking due to initial state of the PLL at zero speed. It means that at low and very low speeds, a sensorless control based on a classical PLL needs some additional information, usually high frequency signals [6], to operate correctly. Contrary, the speed response obtained with Adaline approach is better at low speed thanks to the capacity of learning shown in Fig. 6. We can see that the evolution of the first weight $\mathbf{w}^{(1)}$ (used to calculate the position and the speed) has a direct impact on the dynamic of the speed response. Indeed, by regulating the Adaline's training factor $\eta$ between 0 and 1 , the dynamic of speed response can be

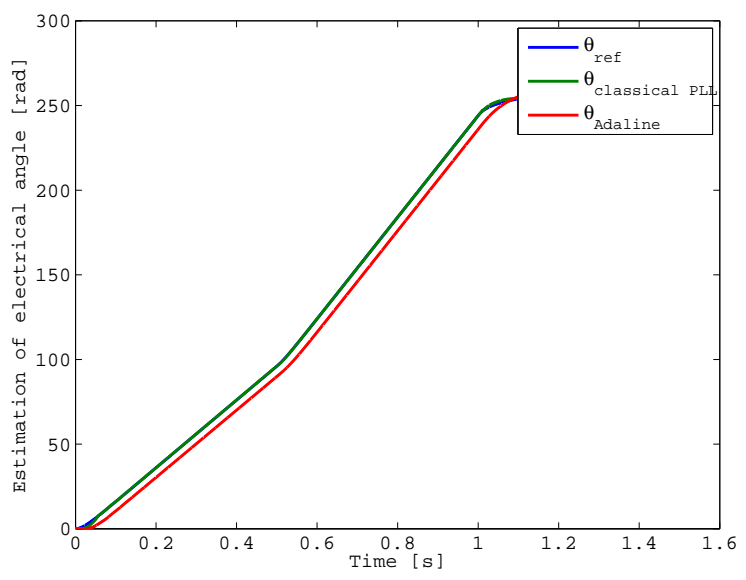

Fig. 5. (Simulation) Electrical angle estimations obtained with a classical PLL in [13] Vs Adaline [rad].

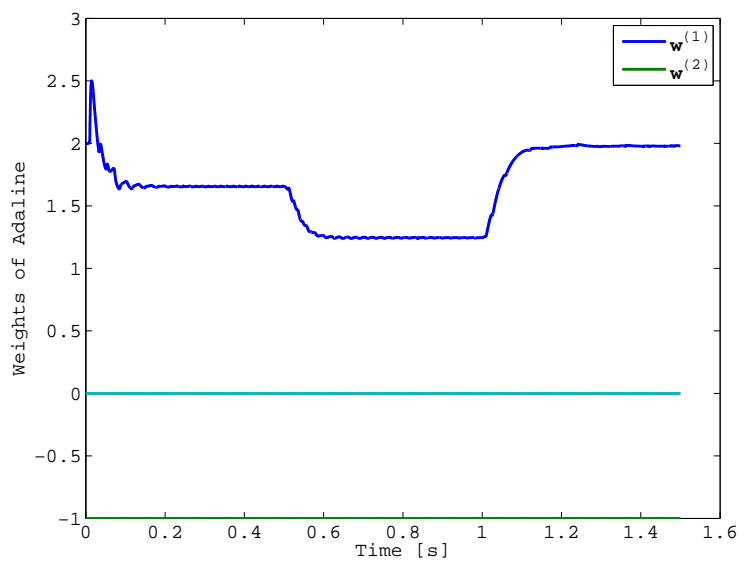

Fig. 6. (Simulation) Evolution of the weights inside of Adaline.

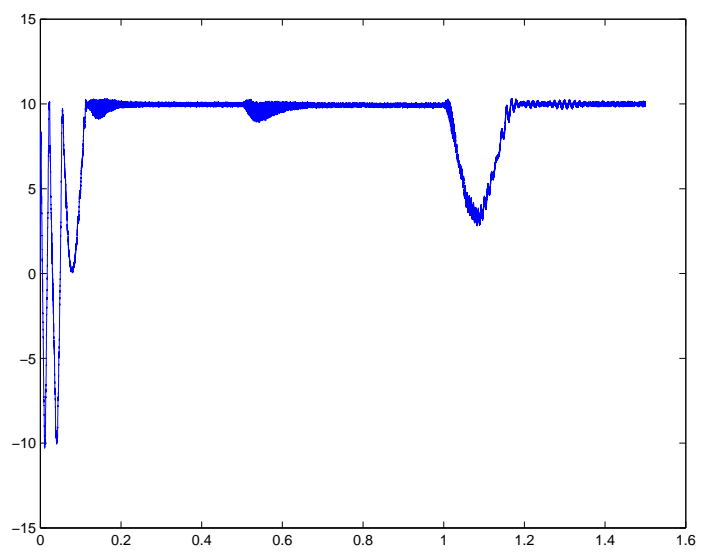

Fig. 7. (Simulation) Torque [N.m].

improved but it is important to know that a high training factor can lead to an unstable response at low speed. In this study, we use an adaptive training factor, ie. a high value for high speed $(\eta=0.003)$ and a low value for low speed $(\eta=0.0005)$.

The torque and the phase currents are reported in Fig. 7 and Fig. 8 respectively. 10 [N.m] is the setup value of the torque. 


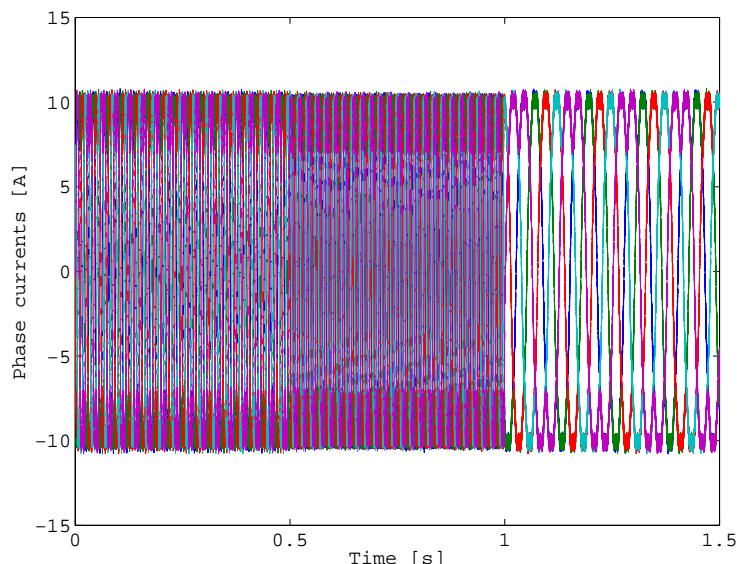

Fig. 8. (Simulation) Phase currents [A].

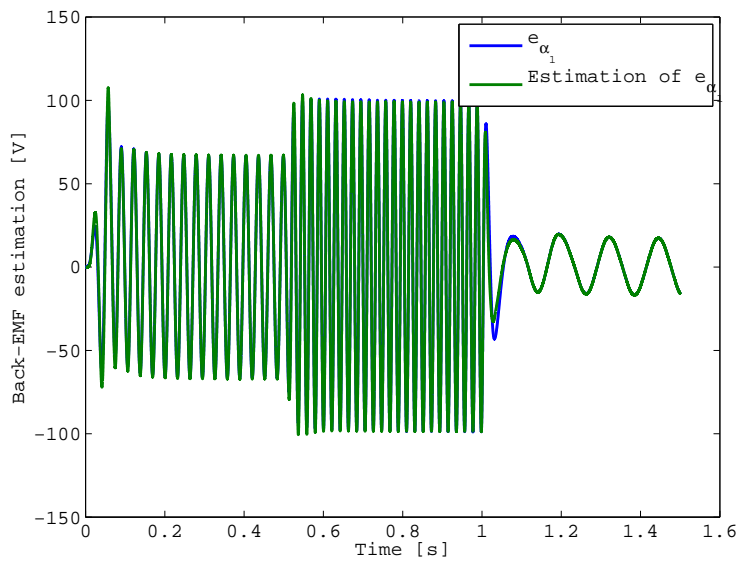

Fig. 9. (Simulation) Estimation of the back-EMF $\hat{e}_{\alpha_{1}}[\mathrm{~V}]$.

The torque ripple at high frequencies is due to the PWM and the imperfection of the current controllers. This result verifies the robustness (face to a speed variation) of the proposed selfsensing control method based on the Adaline.

An estimation of the back-EMF $\hat{e}_{\alpha_{1}}$ is given in Fig. 9. It can be concluded that a fast and stable convergence has been achieved and the proposed method is suitable for real-time implementation. This is important and could be considered as a very positive key of the proposed method because all methods based on learning process will require generally a huge calculus time and almost of them are not suitable for real-time applications.

\section{FIRST EXPERIMENTAL RESUlTS}

An experimental test-bed based on dSPACE1005 is used to test the algorithm. The PWM switching frequency is $10 \mathrm{Khz}$. An electromagnetic powder brake is employed as load.

Fig. 10 shows the rotor speed estimations. A variation from $60[\mathrm{rad} / \mathrm{s}]$ to $30[\mathrm{rad} / \mathrm{s}]$ is made to verify the robustness and the dynamic of the drive. It can be noticed that the speed obtained with Adaline approach is better than the one obtained with the method presented in [13], specially at $30[\mathrm{rad} / \mathrm{s}]$, in

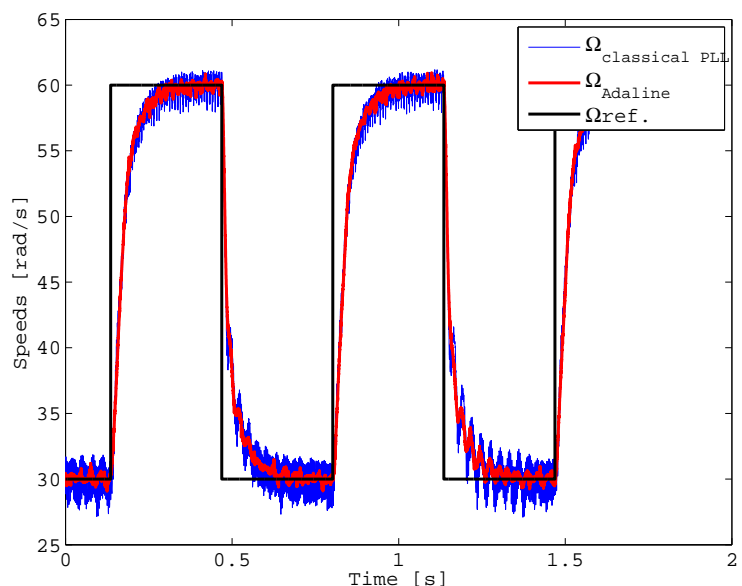

Fig. 10. (Experimental) Speed estimations obtained with a classical PLL in [13] Vs Adaline.

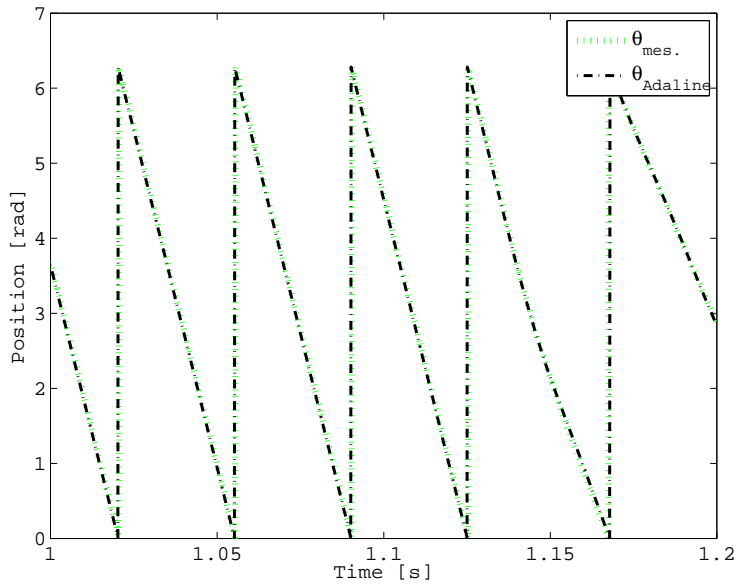

Fig. 11. (Experimental) Position estimation obtained with Adaline (a zoom between $1 \mathrm{~s}$ and $1.2 \mathrm{~s}$ ).

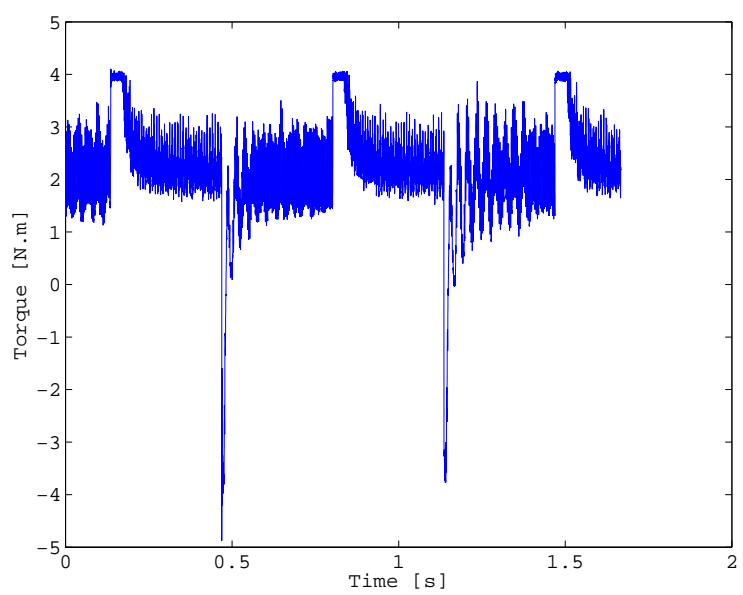

Fig. 12. (Experimental) Electromagnetic torque [N.m].

term of ripple. The response time is almost the same for two methods. The rotor position estimation is reported in Fig. 11. 


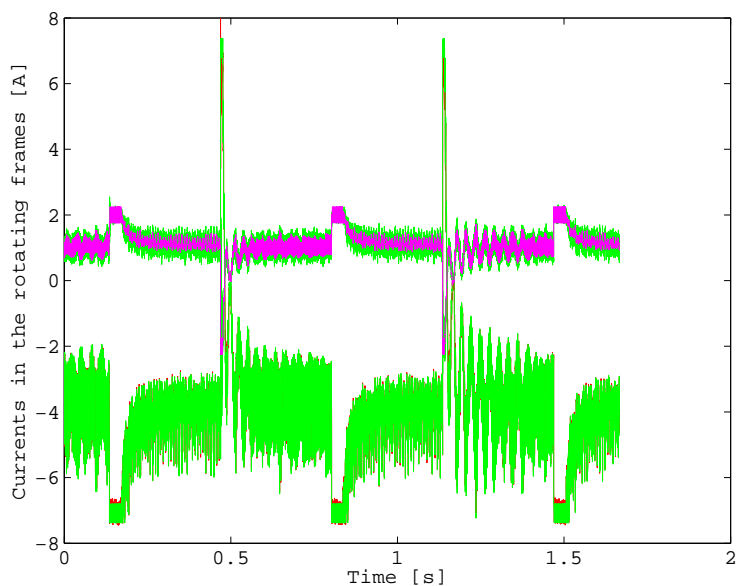

Fig. 13. (Experimental) Currents in the rotating frame [A].

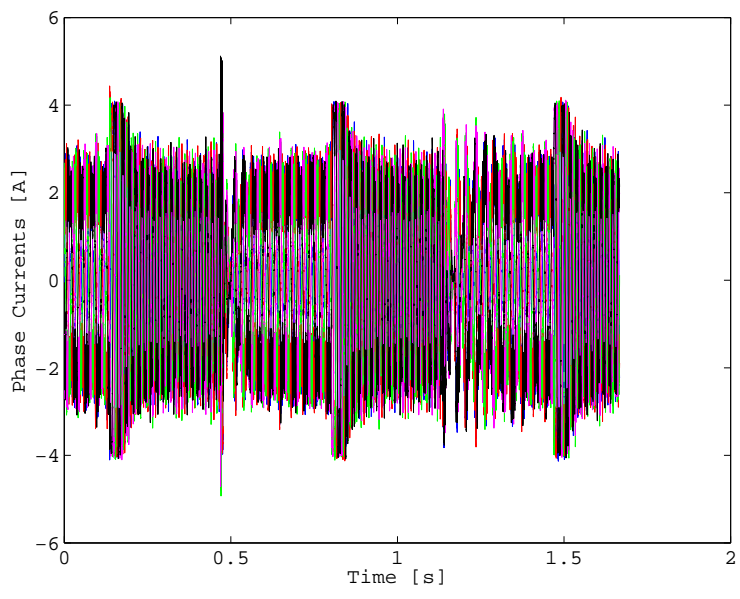

Fig. 14. (Experimental) Phase currents [A].

It is possible to conclude that a good performance has been achieved with the proposed approach.

The estimated torque, the dq currents and the phase currents are shown in Fig. 12, Fig. 13 and Fig. 14, respectively. As the back-EMF is trapezoidal, the 3rd harmonic is used to produce the torque. Due to the limit of test conditions, the maximum torque is fixed to 4 [N.m] explaining a saturation during acceleration from $30[\mathrm{rad} / \mathrm{s}]$ to $60[\mathrm{rad} / \mathrm{s}]$. We can observe that there is a high peak of torque and dq currents during the transient state from $60[\mathrm{rad} / \mathrm{s}]$ to $30[\mathrm{rad} / \mathrm{s}]$ because of the infinite dynamic of the speed reference. These high peaks of torque and current could be reduced by using a lowpass filter for the desired speed. The time constant of this filter can be fixed to two times greater than the one of the speed controller.

\section{CONCLUSION}

This paper has investigated a possibility to use an Adaline neural networks for the sensorless control of 5-phase PMSM drives. The speed response is better, specially at low speed, in term of ripple by using Adaline instead of a classical PLL from which the drawback is the PI regulators. Moreover, a better response of the Adaline is obtained compared to the PLL when starting from unknown states. Some simulation and experimental results have been carried out to validate the proposed method.

\section{REFERENCES}

[1] E. Levi, "Multiphase electric machines for variable-speed applications," IEEE Trans. on Industrial Electronics, vol. 55, no. 5, pp. 1893-1909, 2008.

[2] X. Kestelyn and E. Semail, "A vectorial approach for generation of optimal current references for multiphase permanent-magnet synchronous machines in real time," IEEE Trans. on Industrial Electronics, vol. 58, no. 11, pp. 5057-5065, 2011.

[3] N. K. Nguyen, F. Meinguet, E. Semail, and X. Kestelyn, "Fault-tolerant operation of an open-end winding five-phase pmsm drive with shortcircuit inverter fault," Industrial Electronics, IEEE Transactions on, vol. 63, no. 1, pp. 595-605, 2016.

[4] E. Semail, A. Bouscayrol, and J. P. Hautier, "Vectorial formalism for analysis and design of polyphase synchronous machines," European Physical Journal-Applied Physics, vol. 22, no. 3, pp. 207-220, 2003.

[5] F. Betin, G. A. Capolino, D. Casadei, B. Kawkabani, R. I. Bojoi, L. Harnefors, E. Levi, L. Parsa, and B. Fahimi, "Trends in electrical machines control: Samples for classical, sensorless, and fault-tolerant techniques," Industrial Electronics Magazine, IEEE, vol. 8, no. 2, pp. 43-55, 2014.

[6] F. Gabriel, F. De Belie, X. Neyt, and P. Lataire, "High-frequency issues using rotating voltage injections intended for position self-sensing," IEEE Trans. on Industrial Electronics, vol. 60, no. 12, pp. 5447-5457, 2013.

[7] Y. Shih-Chin, "Saliency-based position estimation of permanent-magnet synchronous machines using square-wave voltage injection with a single current sensor," Industry Applications, IEEE Transactions on, vol. 51, no. 2, pp. 1561-1571, 2015.

[8] L. Alberti, N. Bianchi, and S. Bolognani, "Comparison of different synchronous machines for sensorless drives," in Industrial Electronics Society, IECON 2013 - 39th Annual Conference of the IEEE, pp. 82208226.

[9] N. Bianchi, S. Bolognani, A. Faggion, and E. Fornasiero, "Analysis and experimental tests of the sensorless capability of a fractional-slot inset pm motor," Industry Applications, IEEE Transactions on, vol. 51, no. 1, pp. 224-231, 2015.

[10] A. Del Pizzo, C. Olivieri, F. Ciancetta, M. Tursini, and N. Rotondale, "Development issues of a neural observer-based and fault-adaptive sensorless strategy for a multiphase bldc motor," in Power Electronics, Electrical Drives, Automation and Motion (SPEEDAM), 2014 International Symposium on, pp. 1166-1173.

[11] L. Parsa and H. A. Toliyat, "Sensorless direct torque control of fivephase interior permanent-magnet motor drives," Industry Applications, IEEE Transactions on, vol. 43, no. 4, pp. 952-959, 2007.

[12] C. Hung-Chi, H. Chih-Hao, and C. Da-Kai, "Position sensorless control for five-phase permanent-magnet synchronous motors," in Advanced Intelligent Mechatronics (AIM), 2014 IEEE/ASME International Conference on, pp. 794-799.

[13] F. De Belie, X. Kestelyn, and N. K. Nguyen, "Fault-tolerant optimalcurrent torque-controlled five-phase pmsms with open-circuited phases: Position self-sensing operation," in Vehicle Power and Propulsion Conference (VPPC), 2014 IEEE, 2014, pp. 1-6.

[14] B. Widrow and E. Walach, Adaptive Inverse Control. Prentice-Hall, Inc., 1996.

[15] P. Dash, D. Swain, A. Routray, and A. Liew, "An adaptive neural network approach for the estimation of power system frequency," Electric Power Systems Research, vol. 41, pp. 203-210, 1997.

[16] N. K. Nguyen, D. Flieller, P. Wira, and D. Ould Abdeslam, "Neural networks for phase and symmetrical components estimation in power systems," in 35th Annual Conference of the IEEE Industrial Electronics Society (IECON'09), Porto, Portugal, 2009, pp. 1743-1749.

[17] D. Flieller, N. K. Nguyen, P. Wira, G. Sturtzer, D. O. Abdeslam, and J. Merckle, "A self-learning solution for torque ripple reduction for nonsinusoidal permanent-magnet motor drives based on artificial neural networks," IEEE Trans. on Industrial Electronics, vol. 61, no. 2, pp. 655-666, 2014. 